\title{
Cytogenetic characterization of Melipona rufiventris Lepeletier 1836 and Melipona mondury Smith 1863 (Hymenoptera, Apidae) by C banding and fluorochromes staining
}

\author{
Denilce Meneses Lopes, Sílvia das Graças Pompolo, Lúcio Antônio de Oliveira Campos \\ and Mara Garcia Tavares \\ Departamento de Biologia Geral, Universidade Federal de Viçosa, Viçosa, MG, Brazil.
}

\begin{abstract}
The stingless bees Melipona rufiventris and $M$. mondury were analyzed cytogenetically by conventional staining with Giemsa, C-banding and sequential staining with the fluorochromes $\mathrm{CMA}_{3} / \mathrm{DA} / \mathrm{DAPI}$. Both species presented $2 \mathrm{n}=18$ and $n=9$, except for one colony of $M$. rufiventris, in which some individuals had $2 n=19$ due to the presence of a $B$ chromosome. After Giemsa staining and C-banding the chromosomes appeared very condensed and presented a high heterochromatic content, making it difficult to localize the centromere and therefore to visualize the chromosomes morphology. The constitutive heterochromatin was located in interstitial chromosome regions covering most of the chromosomes extension and consisted mainly of AT, as shown by DAPI staining. The euchromatin was restricted to the chromosome extremities and was GC-rich, as evidenced by $\mathrm{CMA}_{3}$ staining. The $\mathrm{B}$ chromosome was $\mathrm{CMA}_{3}$-negative and DAPI-positive, a heterochromatic constitution similar to that of the $\mathrm{A}$ genome chromosomes.
\end{abstract}

Key words: Melipona, stingless bees, B chromosomes, fluorochromes, C-banding.

Received: June 14, 2007; Accepted: September 18, 2007.

\section{Introduction}

The bees of the subtribe Meliponini, known as indigenous stingless bees, are among the main pollinators of several ecosystems. They are important agents in the conservation of many plant species and consequently of the animals that depend on these plants. Nevertheless, many stingless bees have had their populations reduced due to the destruction of their natural environment. The populations of Melipona rufiventris of Minas Gerais, for example, have been so reduced that the species is now considered endangered in this state (Campos, 1998).

Until recently, populations of $M$. rufiventris found in southeastern Brazil were considered to be a single species. Melo (2003), however, concluded that the morphological variations observed among individuals from different regions were very evident and suggested that the form found in the Cerrado biome should be called $M$. rufiventris Lepeletier 1836, while the form found in the Atlantic Forest should be called M. mondury Smith 1863. Nevertheless, it is difficult to distinguish both species based on morphological characters (F.A. Silveira, personal communication). Thus, the use of additional biological data is important for a

Send correspondence to Mara Garcia Tavares. Departamento de Biologia Geral, Universidade Federal de Viçosa, 36570-000 Viçosa, MG, Brazil. E-mail: mtavares@ufv.br. better definition of the taxonomic status of these species. Cytogenetic analyses have already greatly contributed to taxonomic, phylogenetic and evolutionary studies of Hymenoptera (Imai et al., 1988, Rocha et al., 2002).

Kerr (1948) performed the first cytogenetic studies analyzing species of the genus Melipona Illiger, 1806. This author described the karyotypes of M. marginata and $M$. quadrifasciata. At present, from 36 Melipona species known (Silveira et al., 2002; Melo, 2003) 16 have already been analyzed cytogenetically (reviewed in Rocha et al., 2003). The species of this genus generally present $2 \mathrm{n}=18$ and $\mathrm{n}=9$ chromosomes. In M. quinquefasciata, however, variations of $2 n=19-22$ and $n=9-13$ were observed in females and males, respectively (Pompolo, 1992; M.P. Rocha, personal communication). Rocha (2002) considered that the normal complement of this species was $2 n=18$ and that the differences found would be due to the presence of B chromosomes. Nevertheless, B chromosomes are quite rare in Hymenoptera and have only been observed in two stingless bee species, $M$. quinquefasciata and Partamona helleri (Costa et al., 1992; Brito et al., 1997; Tosta et al., 2004).

The aim of this study was to perform a comparative cytogenetic analysis of M. rufiventris and M. mondury which have been considered as a single species until recently. The data obtained could further contribute to understanding the karyotype evolution in the genus Melipona. 


\section{Materials and Methods}

Six Melipona rufiventris and five M. mondury colonies were analyzed. M. rufiventris colonies were collected in Guimarânia (MG), whereas M. mondury were collected in Diogo Vasconcelos (MG), Rio Vermelho (MG), Itamarandiba (MG) and Rio Bonito (RJ). Fifty-five individuals of $M$. rufiventris (43 females and 12 males) and 30 specimens of $M$. mondury ( 28 females and 2 males) were studied. For each individual, an average of ten metaphases was analyzed.

Metaphase chromosomes were obtained from cerebral ganglia of larvae in the final defecation stage (Imai et al., 1988). Conventional Giemsa staining and C-banding (BSG method: barium hydroxide/saline solution/Giemsa) were performed as described in Rocha and Pompolo (1998). Sequential staining with the fluorochromes chromomycin $\mathrm{A}_{3}\left(\mathrm{CMA}_{3}\right)$, distamycin $\mathrm{A}$ and 4'-6-diamindino2-phenylindole (DAPI) was performed according to Schweizer (1980).

Metaphases were analyzed under a light field and epifluorescence microscope and the karyotypes were mounted by pairing chromosomes in decreasing size order.

\section{Results and Discussion}

Melipona rufiventris and $M$. mondury presented the same chromosome numbers already described for other Melipona species: $2 \mathrm{n}=18$ in females and $\mathrm{n}=9$ in males (reviewed in Rocha et al., 2003). C-banding revealed a high content of heterochromatin in the chromosomes of $M$. rufiventris and $M$. mondury located in the interstitial regions and extending through most of the chromosomes arms (Figure 1). The exact location of the centromere could not be assessed, making it impossible to define the chromosomes morphology. The euchromatic regions were restricted to the chromosomes extremities. One of the homologues of pair 1 was larger in both species due to an additional quantity of heterochromatin (Figure 1).

Although species of the Melipona genus present a conserved number of chromosomes, a wide variation in heterochromatic content allowed their separation into two groups. Group I comprises species with low heterochromatic content and group II reunites species with a high heterochromatic content (Rocha and Pompolo, 1998; Rocha et al., 2002). C-banding revealed that $M$. rufiventris and M. mondury presented a high heterochromatic content and can thus be included in group II together with M. capixaba, M. scutellaris, M. captiosa, M. crinita, M. compressipes and M. seminigra fuscopilosa.

The euchromatic regions in both species studied herein presented clear associations during prometaphase, which have previously been found in other group II species. Rocha et al. (2002) suggested that high heterochromatin contents and euchromatin associations resulting in "U" or chain configurations are derived characters that characterize species from group II as a natural group or clade within Melipona.

Sequential staining with fluorochromes in $M$. rufiventris and $M$. mondury revealed the same patterns already described in other Melipona species of group II. The heterochromatin was intensely stained with DAPI indicating its richness in $\mathrm{AT}$, while the euchromatin was $\mathrm{CMA}_{3}$ positive, demonstrating a predominance of CG (Figure 2).

In both species, pair 1 was strongly stained with $\mathrm{CMA}_{3}$, which may be related with the nucleolar organizer region (NOR), as already described in Trypoxylon albitarse (Araújo et al., 2000), Plebeia (Maffei et al., 2001), Melipona compressipes (Rocha et al., 2002) and Partamona peckolti (Brito et al., 2003). In all these species, the NORs where $\mathrm{CMA}_{3}$-positive.

The presence of one $\mathrm{B}$ chromosome was observed in one colony of M. rufiventris (colony $16 \mathrm{G}$ ) and for this rea-
A

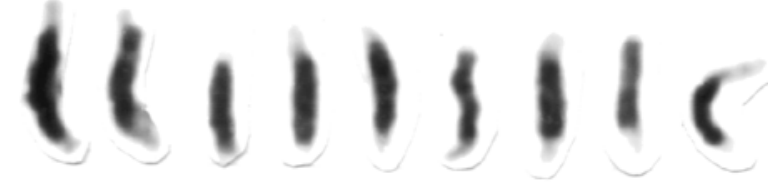

B

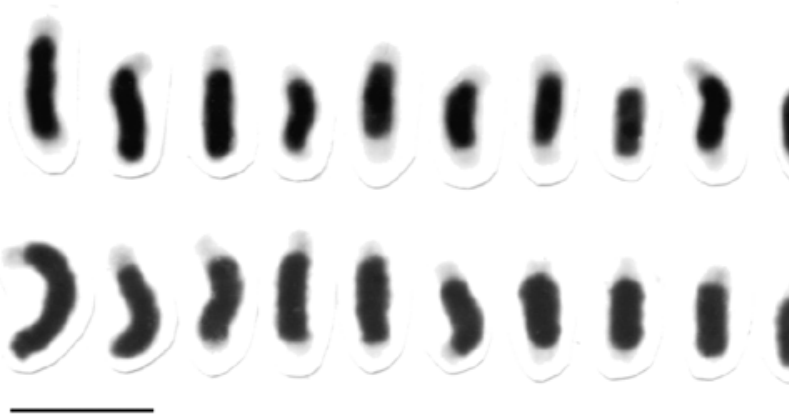

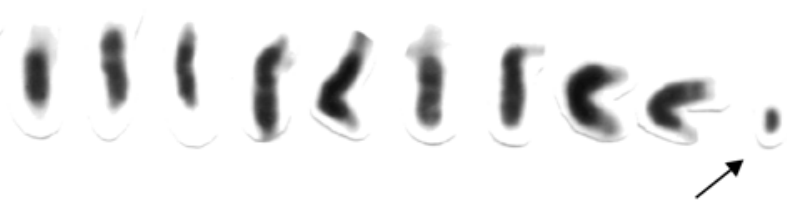
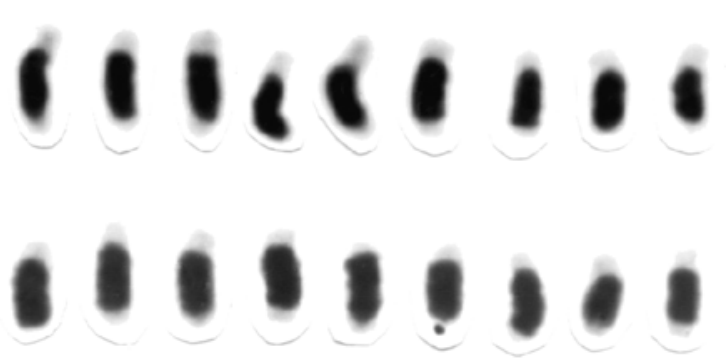

Figure 1 - Karyotypes and C-banding patterns of Melipona rufiventris (A, B) and M. mondury (C). The arrow indicates the B chromosome. Scale bar $=5 \mu \mathrm{m}$. 


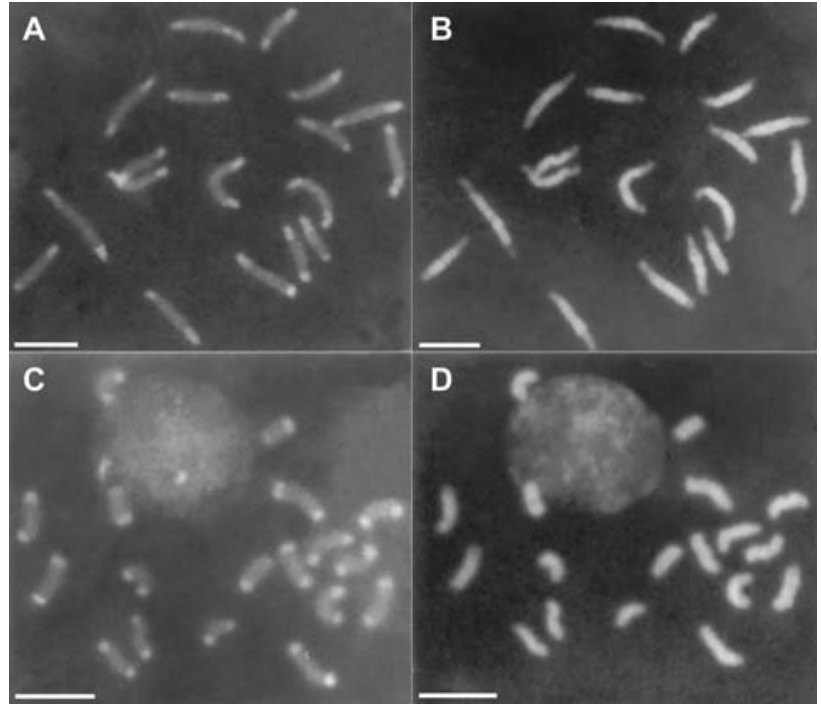

Figure 2 - Sequential staining with $\mathrm{CMA}_{3} / \mathrm{DA} / \mathrm{DAPI}$ in metaphases of Melipona rufiventris (A: $\mathrm{CMA}_{3}$; $\mathrm{B}$ : DAPI) and M. mondury $\left(\mathrm{C}: \mathrm{CMA}_{3}\right.$; D: DAPI). Scale bar $=5 \mu \mathrm{m}$.

son a larger number of individuals from this colony was analyzed. This chromosome was observed in both males and females and was present in 14 of the 25 individuals analyzed. It was smaller than the chromosomes of the A genome and was strongly stained with both Giemsa and C-banding (Figure 1). The apparent completely heterochromatic nature of the $\mathrm{B}$ chromosome hindered the detailed observation of its morphology.

$\mathrm{B}$ chromosomes have been previously described in only two other stingless bee species. Two types of B chromosomes, varying from 0 to 4 among individuals, were found in Partamona helleri (Costa et al., 1992; Brito et al., 1997; Tosta et al., 2004). In Melipona quinquefasciata, the number of B chromosomes ranged from 1 to 4 in females and from 0 to 4 in males (Pompolo, 1992, M.P. Rocha, personal communication). This variation was observed among individuals of the same colony as well as among different cell types of the same individual.

In $M$. rufiventris, one B chromosome was found in some individuals and there was no variation among cells of each individual. Considering that this chromosome was observed in males and females, we may conclude that, at least in this colony, it is being transmitted by the queen because the males are derived from non-fertilized eggs. This hypothesis is further strengthened by the fact that workers presented only one B chromosome. Nevertheless, as this chromosome was observed in only one colony, additional studies may shed light on its origin and behaviour in this species.

This B chromosome did not stain with chromomycin and its heterochromatic region was positively stained with DAPI, a constitution similar to that of the A genome chromosomes (rich in AT) (Figure 3).

Little can be said about the origin of the B chromosome of $M$. rufiventris. In general, B chromosomes can

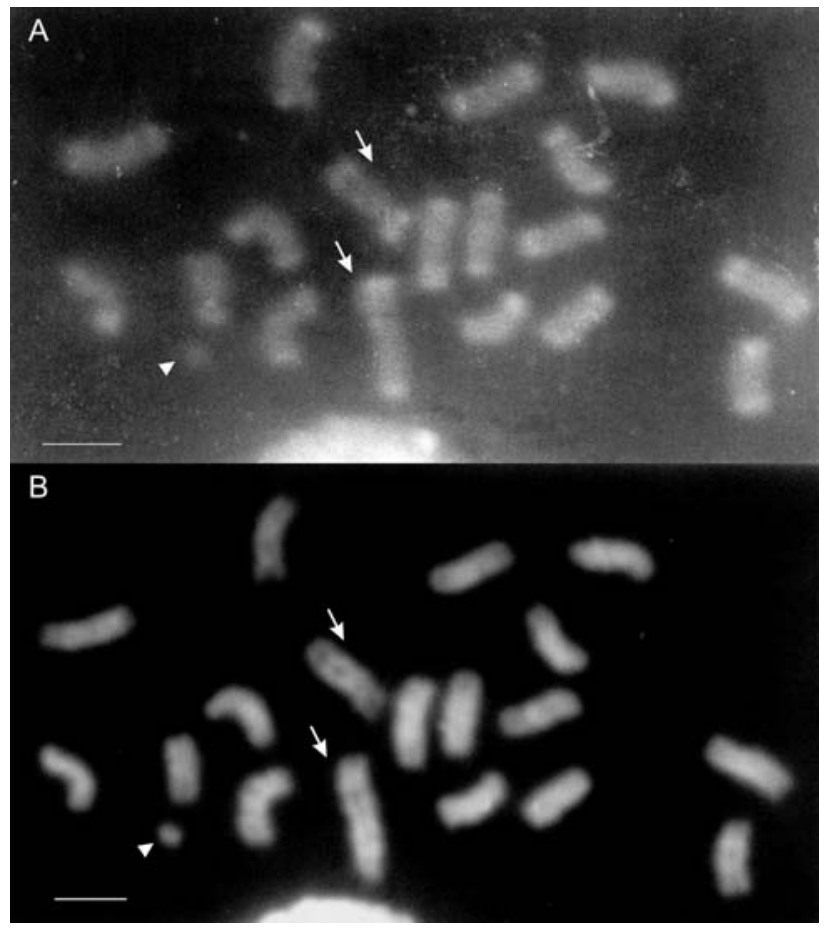

Figure 3 - Sequential staining with $\mathrm{CMA}_{3} / \mathrm{DA} / \mathrm{DAPI}$ in metaphases of Melipona rufiventris (A: $\mathrm{CMA}_{3}$; $\mathrm{B}$ : DAPI). The arrows indicate chromosome pair 1 and the arrowhead indicates the B chromosome. Scale bar $=5 \mu \mathrm{m}$.

originate in an intraspecific manner, through fragmentation of autosomes or sex chromosomes, or in an interspecific manner by hybridization or through the action of transposable elements (Camacho et al., 2000). In M. rufiventris, the B chromosome may have derived from the A genome, through fission in the heterochromatic region of the heteromorphic chromosome pair (pair 1). This idea is supported by the similar responses of the heterochromatin of the non-homologous portion of the heteromorphic pair and of the $\mathrm{B}$ chromosome to the fluorochromes used $\left(\mathrm{CMA}_{3}{ }^{-} \mathrm{e}\right.$ DAPI+). Heteromorphysms have also been observed in other Melipona species (Rocha et al., 2002) and even in M. rufiventris colonies that did not present $\mathrm{B}$ chromosomes. This does not invalidate the possibility that this B chromosome originated as suggested above because B chromosomes may have been lost during evolution and new colonies could have been formed from individuals without $\mathrm{B}$ chromosomes if they had a low frequency in the original colony. Further studies involving the analysis of additional colonies of M. rufiventris will be necessary to provide more data regarding the origin of the $\mathrm{B}$ chromosomes in this species.

\section{Acknowledgments}

The authors thank PROBIO/BIRD/GEF, MMA and $\mathrm{CNPq}$ for the financial support given to the subproject "Elaboração de plano de manejo para a uruçu amarela 
(Melipona rufiventris Lepeletier, 1836)"; FAPEMIG for financial support to the project "CBB 827/04" and CAPES for supporting D.M. Lopes.

\section{References}

Araújo, SMR, Pompolo SG, Dergam JA and Campos LAO (2000) The B chromosome system of Tripoxylon (trypargilum) albitarse (Hymenoptera, Sphecidae). 1. Banding analysis. Cytobios 101:7-13.

Brito RM, Costa MA and Pompolo SG (1997) Characterization and distribution of supernumerary chromosomes in 23 colonies of Partamona helleri (Hymenoptera, Apidae, Meliponinae). Rev Bras Genet 20:185-188.

Brito RM, Pompolo SG, Caixeiro APA, Pompolo SG and Azevedo GG (2003) Cytogenetic data of Partamona peckolti (Hymenoptera, Apidae Meliponini) by $\mathrm{C}$ banding and

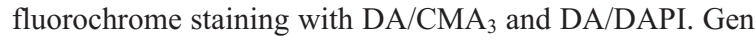
Mol Biol 26:53-57.

Camacho JPM, Sharbel TF and Beukeboom LW (2000) B-chromosome evolution. Phil Trans R Soc Lond B 355:163-178.

Campos LAO (1998) Melipona rufiventris Lepeletier, 1836. In: Machado ABM, Fonseca GAB, Machado RB, Aguiar LMS and Lins LV (eds) Livro Vermelho das Espécies Ameaçadas de Extinção da Fauna de Minas Gerais. Biodiversitas, Belo Horizonte, pp 560-561.

Costa MA, Pompolo SG and Campos LAO (1992) Supernumerary chromosomes in Partamona helleri (Hymenoptera, Apidae, Meliponinae). Rev Bras Genet 15:801-806.

Imai HT, Taylor RW, Crosland MWJ and Crozier RH (1988) Modes of spontaneous chromosomal mutation and karyotype evolution in ants with reference to the minimum interaction hypothesis. Jpn J Genet 63:159-185.

Kerr WE (1948) Estudos sobre o gênero Melipona. Anais da Escola Superior de Agricultura "Luiz de Queiroz" 5:182276.
Maffei EMD, Silva-Jr JC, Caixeiro APA, Rocha MP and Dergam JA (2001) Silver staining of nucleolar organizer regions (NORs) in some species of Hymenoptera (bees and parasitic wasps) and Coleoptera (lady beetle). Cytobios 104:109-125.

Melo GAR (2003) Notas sobre meliponíneos neotropicais (Hymenoptera, Apidae), com a descrição de três novas espécies. In: Melo GAR and Santos IA (eds) Apoidea Neotropica. Homenagem aos 90 Anos de Jesus Santiago Moure. UNESC, Santa Catarina, pp 85-92 (Abstract in English).

Pompolo SG (1992) Estudos citogenéticos em meliponinae. Naturalia (special issue):62-66 (No Abstract in English).

Rocha MP and Pompolo SG (1998) Karyotypes and heterochromatin variation (C-bands) in Melipona species (Hymenoptera, Apidae, Meliponinae). Gen Mol Biol 21:41-45.

Rocha MP, Pompolo SG, Dergam JA, Fernandes A and Campos LAO (2002) DNA characterization and karyotypic evolution in the bee genus Melipona (Hymenoptera Meliponini). Hereditas 136:19-27.

Rocha PB, Pompolo SG and Campos LAO (2003) Citogenética da tribo Meliponini (Hymenoptera, Apidae). In: Melo GAR and Santos IA (eds) Apoidea Neotropica. Homenagem aos 90 Anos de Jesus Santiago Moure. UNESC, Santa Catarina, pp 311-320 (Abstract in English).

Schweizer D (1980) Simultaneous fluorescent staining of R bands and specific heterochromatic region (DA-DAPI bands) in human chromosomes. Cytogenet Cell Genet 27:190-193.

Silveira FA, Melo GAR and Almeida EAB (2002) Abelhas Brasileiras: Sistemática e Identificação. Fundação Araucária, Belo Horizonte, 253 pp.

Tosta VC, Fernandes-Salomão TM, Tavares MG, Pompolo SG, Barros EG and Campos LAO (2004) A RAPD marker associated with B chromosomes in Partamona helleri (Hymenoptera, Apidae). Cytogenet Genome Res 106:279283.

Associate Editor: Yatiyo Yonenaga-Yassuda 